\title{
The Influence of Pursed Lip Breathing on Dyspnea, Oxygen Saturation and Activity Tolerance on COPD Patient: Systematic Review
}

\author{
Rudi Hariyono \\ Faculty of Nursing, Universitas Airlangga \\ Surabaya, Indonesia \\ rudihariyono86@gmail.com \\ Putu Sintya Arlinda Arsa \\ Faculty of Nursing, Universitas Airlangga \\ Surabaya, Indonesia
}

\author{
Shelfi Dwi Retnani Putri Santoso \\ Faculty of Nursing, Universitas Airlangga \\ Surabaya, Indonesia \\ shelfi.dr.putri@gmail.com \\ Fahrur Rozi \\ Faculty of Nursing, Universitas Airlangga \\ Surabaya, Indonesia
}

\begin{abstract}
Systematic review has the purpose to know the influence of pursed lip breathing on dyspnea, oxygen saturation and activity tolerance on COPD patients taken from 15 journals. Information related to this research was found on some databases such as MEDLINE journals, PubMed, CINAHL, Ebsco, Elsevier ScienceDirect journal respiration in which collection of abstract and research that was identified started from 2000 until the 2015. Pursed lip breathing was an effective therapy in increasing oxygen saturation up to $1.2 \%$, decreased dyspnea and tolerance activity. Pursed lip breathing was an easy and inexpensive therapy, which might be applied in the patients' lives with COPD to overcome gas exchange and respiratory pattern disorders
\end{abstract}

Keywords : chronic obstructive pulmonary disease, pursed lip breathing, oxygen saturation, dyspnea, tolerance activities

\section{INTRODUCTION}

The chronic obstructive pulmonary disease is a disease that is preventable and also curable; nevertheless, COPD is the fourth leading cause of death in the world. The severity of COPD is defined as the rate of airflow limitation expiration and air flow obstruction. This matter is important for diagnosis, and the Force Vital Expiration 1 (FEV1) can provide a useful overview to find out the severity and pathological changes in COPD. However, the FEV1 is not significantly correlated to the change of dyspnea[1]. Chronic dyspnea is constant and unpleasant sensations when experiencing shortness of breath, the negative effects for patients' health are suffering from progressive pulmonary disease such as chronic obstructive pulmonary disease, it had the status of functional decline and patients perhaps experience social isolation[2].

There are approximately 600.000 of the Britons or people who live in the United Kingdom with chronic obstructive pulmonary disease and a study reporting that shortness of breath experienced during performing tasks is one of the most paralyzing symptoms in COPD patients. It is often in a simple occurrence as walking to their home. Various techniques had been used to overcome the limitations of activity and dyspnea, one of these techniques was an instruction for practicing breathing patterns[2].

Pursed lip breathing, is a strategy - training of spontaneous breathing which is often used by patients with COPD to relieve dyspnea. However, the results of pursed-lip breathing usage in reducing dyspnea, improve gas exchange and ventilation efficiency has results that vary between patients. Dynamic hyperinflation caused shortness of breath and created consequences on pulmonary functional capacity limitations in chronic obstructive pulmonary disease. Dynamic hyperinflation has an important role in the limitation of energy in patients with the chronic obstructive pulmonary disease with moderate to severe degree. This phenomenon is somehow associated with limitations of the air flow at the expiration time, expiration time, and the trapped of $\mathrm{CO} 2$ air in the lung, causing respiratory discomfort during exercise or in daily activities. [1] Hyperinflation of the lungs occurs due to the increase and decrease of respiratory muscles power, in which one of the pathologic mechanisms of dyspnea in patients with COPD. On the other hand, the decrease in dynamic hyperinflation can reduce the dyspnea that is based on the varied changes at the end of volume expiration pulmonary[3].

Pursed lip breathing - was conducted to force the pulmonary to do expiration. This is respiratory compensation strategies which are instinctively used during strenuous activity, increased exercise tolerance on the normal subject. While on the health subject, pursed-lip breathing has been proven to increase the volume of tidal, reduce the duration of inspiration, give ventilation while resting and during exercise, extend the expiration time, and lead to the use of the expiration muscles[1] .

The used of pursed lip breathing reported that subjects who experienced chronic obstructive pulmonary disease showed improvements to ventilation and gas exchange. These improvements can be observed from an increase in minutes of ventilation, tidal volume increases, and optimization of functional lung capacity. 


\section{RESEARCH METHODS}

Information related to this research were found on some databases such as MEDLINE journals, PubMed, CINAHL, Ebsco, Elsevier ScienceDirect journal respiration, which was the collection of abstract and research identified starting from 2000 to 2015 . All reference lists consist of the original article in which also conducted some reviews to identify other relevant studies. The entire publication and abstract were made in English which was also made into consideration.

Inclusion criteria that serve as standard sampling were: (1) patients who experienced mild to severe degrees of COPD; (2) pursed lip breathing; (3) the outcomes included: dyspnea, oxygen saturation, and tolerance activities (4) human being as its research subject; and (5) English language journal.

\section{RESULT}

\section{The results of pursed lip breathing influence on dyspnea}

Pursed-lip breathing conducted at rest was able to eliminate dyspnea experienced by the respondents. While the pursed lip breathing was conducted on occasion with workload up to $60 \%$, then the rate of dyspnea score ranges appear in the 3.5 to 9 if measured by VAS. [4]Nevertheless, the dyspnea had a positive correlation with dynamic hyperinflation in TGlittrePLB $(r=0.43 ; p=0.03)$, but there was no correlation found between the absolute change in dyspnea (Non Pursed lip-Pursed-lip breathing on breathing) and absolute changes in dynamic hyperinflation when the 6MWT or TGlittre. Pulmonary Function (FEV1 and FEV1/FVC) there was no significant correlation $(p>0.05)$ with dyspnea. [1] When the degree of dyspnea analyzed after ESWT combined with Pursed-lip breathing, it showed that four patients reported no longer suffering from dyspnea and eight patients were suffered from severe dyspnea. [5] also, the time required to restore a pre-exercise dyspnea experienced significant decline when pursed-lip breathing used for the recovery phase, compared to a normal breath, the average difference was around - $(95 \%$ CI) $24.9(2.8-29.7)$ seconds.

However, this difference was not interpreted as an increase in the activity tolerance or the perception of dyspnea.[2] This kind of parameter was connected to each other in which indicating significant increase during or after the pursed-lip breathing with subjective changes from patients regarding the feeling of dyspnea. There was no parameter that indicates significant correlation with the feeling of dyspnea in patients. Oxygen Saturation had pretty low correlation with VAS score ( $-0.038, p=0.08$, insignificant). Research report showed that there was an increase in the scale of the VAS directly after pursed-lip breathing was conducted with an average $7.8 \mathrm{~mm}-$ (CI 3.3 - 12.2) more than $50 \mathrm{~mm}$. Patients also experienced the increase of VAS scale 5 minutes after conducted a pursedlip breathing with an average $7.6 \mathrm{~mm}-$ (CI $2.6-12.5)$ more than $50 \mathrm{~mm}$.[2] Measurement of dyspnea which was compared between 6MWD with EMT, had increased on a Borg scale after 6MWD which was only found in the Group pursed-lip breathing when compared EMT to control group, 12 weeks later was conducted an observation but not at week-4 and obtained the result $\mathrm{P}=0.05$, a significant difference in week 4 was $p=0.003$.[4] At patients who experienced a change in overall volume in expiration, the end of the chest wall was depicted had correlation on alteration of Borg score that showed the value of dyspnea. ( $2=0.5, \mathrm{p}<0,00002)$ [5].

The influence of pursed lip breathing on oxygen saturation

Changes during the given therapy of pursed lip breathing and 5 minutes after the pursed-lip breathing, the expiration parameter of lung function was FEV1 and FVC showed no significant change (median difference between changes - 11 and $+59 \mathrm{ml}$ ). However, the end-tidal $\mathrm{pCO} 2, \mathrm{SaO} 2$, and frequency of breath, all show a significant increase the pursedlip breathing but the correlation was somehow low. Nevertheless, after five minutes of therapy, pursed lip breathing was used, showed significant improvement, except for the FVC when compared to the FVC in the basal state (average change $105 \mathrm{ml} ; \mathrm{p}=355$ ). Nonetheless, after the used of pursed-lip breathing, there was no significant increase in basal conditions (average change $46 \mathrm{ml} ; \mathrm{p}=0143$ ). Changes in $\mathrm{SaO} 2$ value had an average of 0.97 changes; $95 \%$ CI 0463 to 1,$474 ; p=0.0005 * * *$ that were obtained during pursed-lip breathing, while the average median changes $-0375 ; 95 \% \mathrm{CI}$ 0173 to $0923 \mathrm{p}=0172$ in which got 5 minutes after exercise.

[3] During ESWT exercise, exercise was combined with pursed-lip breathing then 5 minutes after exercise, there was oxygen saturation increase around $1.2 \%$. Oxygen saturation also increased in which measured during $120-240$ seconds during exercise $(\mathrm{p}<0.05)[5]$.

\section{The influence of pursed lip breathing on tolerance activities}

When patients conducted maximum exercise combined with pursed-lip breathing, hence at the end of exercise would cause RR decreased significantly when compared to normal breathing. Changes in RR was the result of the exercise that also significantly decreased during walk and combined with pursed-lip breathing, the average of increase - RR (SD); 6.6 (6.0) and 1.1 (6.2) for a walk without using a pursed-lip breathing and walking combined with pursed-lip breathing, align - average difference (95\% CI); 3.0 (1.7-6.9). [2] When patients used pursed-lip breathing during endurance shuttle walking tests showed the median of walking was 37 seconds or $16 \%$ longer compared to the control group. Studies conducted by Bhatt et al. (2012) at patients who did pursed-lip breathing combined with a 6-minute of walk test (6MWT) there was an increase in the distance when walking for 6 hours (6MWD) in which were compared before and after exercise (Pre-pursed-lip breathing $=408 \pm 89,85 \mathrm{~m}$; Post - pursed lip breathing- $=+445.0472 .31$; the value $\mathrm{p}=0.002$ )[5].

\section{CONCLUSION}

Pursed lip breathing therapy is a non-Pharmacology term which is easy and affordable, and can give the decreasing effect on dyspnea in patients with COPD during exercise; pursed-lip breathing is the breath pattern technique that is very slow and also very deep. COPD patients who used pursed-lip breathing were able to cope with dyspnea well, had their tidal volume increased and decreased the frequency of breathing. [6]The results of the previous study to demonstrate this pursed-lip breathing were able to increase functional exercise tolerance. Improvement in exercise tolerance of COPD patients 
demonstrated the ability to reduce the effort of breathing and also at the same time lowered the effort effectively while suffering from dyspnea[7]. Pursed lip breathing had a quite significant role in the COPD patients who were experiencing dyspnea; the decreased of oxygen saturation and the activity tolerance. [2, 6] Slightly more than half of COPD patients that we observed in several locations during testing: $10 \%$ do spend PLB at rest, $42 \%$ during incremental exercise bike, and 54\% during recovery from exercise. However many research has stated that the PLB is often in COPD patient (1-3), only one previous study report that $22 \%$ of patients studied was spontaneous[13]. PLB intervention has an impact on the tightness when doing exercises in COPD patients[6].

Pursed lip breathing was a therapy that could increase the tolerance activities, decreased the feeling of dyspnea and increased oxygen saturation. Pursed lip breathing was also affordable and easy to be implemented; therefore this therapy was recommended as main therapy for non-pharmacological COPD patients who experienced dyspnea while conducting their activities.

\section{REFERENCES}

[1] S. Raoof and M. B. F. Khan, "Pursed Lips Breathing (PLB) In Chronic Obstructive Pulmonary Disease (COPD)," vol. 19, no. C, pp. 5-8, 1987.

[2] M. A. Nield, G. W. Soo Hoo, J. M. Roper, and S. Santiago, "Efficacy of Pursed-Lips Breathing: A BREATHINGPATTERNRETRAINING STRATEGY FOR DYSPNEA REDUCTION," $J$. Cardiopulm. Rehabil. Prev., vol. 27, no. 4, 2007.

[3] R. Bianchi, F. Gigliotti, and I. Romagnoli, "Chest Wall Kinematics and Breathlessness During PursedLip Breathing in Patients With COPD *," pp. 459465, 2004.

[4] G. A. D. F. Fregonezi, V. R. Resqueti, and R. G. Rous, "Pursed Lips Breathing," pp. 279-282, 2004.

[5] K. Institutet, K. Institutet, and T. Clinics, "Influence of spontaneous pursed lips breathing on walking endurance and oxygen saturation in patients with moderate to severe chronic obstructive pulmonary disease," pp. 675-683, 2008.

[6] C. Laura, P. De Araujo, M. Karloh, C. Martins, M. Palú,andA.F.Mayer,"PURSED-LIPS

BREATHING REDUCES DYNAMIC HYPERINFLATION INDUCED BY ACTIVITIES OF DAILY LIVING TEST IN PATIENTS WITH CHRONICOBSTRUCTIVEPULMONARY

DISEASE : A RANDOMIZED CROSS- OVER STUDY," pp. 957-962, 2015.

[7] J. C. Stoltzfus, T. Dey, S. Nanda, and R. Guleria, "Volitional pursed lips breathing in patients with stable chronic obstructive pulmonary disease improves exercise capacity," 2012. 